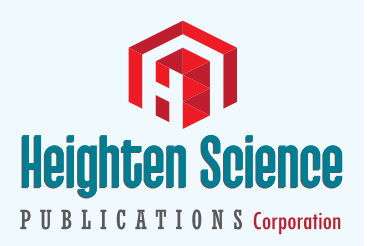

ISSN

2640-2866
*Address for Correspondence: Marzia Cottini, Department of Heart and Vessels, Cardiac Surgery Unit, "S. Camillo-Forlanini" Hospital, Circonvallazione Gianicolense 87, 00152, Rome, Italy, Tel: +39-347-3245331, Fax +39-06-58704511 Email: mailto:marzia.cottini@gmail.com

Submitted: 03 August 2017

Approved: 18 September 2017

Published: 20 September 2017

Copyright: @ 2017 Cottini M, et al. This is an open access article distributed under the Creative Commons Attribution License, which permits unrestricted use, distribution, and reproduction in any medium, provided the original work is properly cited.

Keywords: Valve replacement; Transapical valve; Anaesthesia; Octogenarians

Check for updates
Case Report

\section{Evolution of anaesthesia in} transapical aortic valve implantation Running head: Anaesthesia and transcatheter valve

\author{
Marzia Cottini*, Lappa A, Donfrancesco S and Francesco \\ Musumeci \\ Department of Heart and Vessels, Cardiac Surgery Unit and Heart Transplantation Centre, "S. \\ Camillo-Forlanini" Hospital, 00152 Rome, Italy
}

\section{Abstract}

The Transcatheter Aortic Valve Implantation (TAVI) had emerged more and more in the last twenty years. According to the scientific literature, this is an approved, suitable and alternative therapeutic choice to conventional surgery for aortic valve disease in high risk patients. The most of patients are octogenarians or nonagenarians, with multiple comorbidities (neurological,vascular,oncologic, haematological, etc). The evolution of TAVI techniques and its devices have improved the quality of results and reduced the peri- and post-procedural complications. Cardiac anaesthesia and analgesia in TAVI patients is very important and fundamental to a quickly and complete clinical restoring after the procedure. An optimal balance of drugs and peri-procedural management could reduce the neurological events (such as delirium), the days of hospitalization and the admission of intensive care unit. According to our experience in transapical approach, the low dose of propofol and desflurane allowed to optimal cardiac anaesthesia and rapid mechanical ventilation weaning in complex patient undergone to transcatheter valve implantation with transapical approach. Moreover, our protocol reduced considerably the incidence of perioperative delirium.

\section{Introduction}

The cardiac patients become more and more complex because of their age (octogenarians or nonagenarians) and their co-pathologies both (neurological,oncologica l,heamatological,vascular,and so on) [1]. The emerging number of high-risk patients with heart valve disease had required an alternative therapeutic choice to conventional surgery due to the mortality and morbidities [2]. About twenty years ago the transcatheter aortic valve implantation (TAVI) was established. At the beginning, the first TAVI generation experience was complicated to frequent procedural complications but the lower profile of second generation TAVI improved the quality of procedures and patient outcome (Table 1). Recently, the third generation of TAVI had optimal results, good periprocedural and postprocedural data, low days of hospitalization and the worldwide trend was to extend the TAVI to low risk patients but it will require rigorous evidence-based medicine validation [1-6].

\section{Anesthetic management of TAVI}

In the most of centers, there were two available technologies, the balloonexpandable Edwards/Sapien Bioprosthesis [5] and the self-expandable CoreValve [6], with multiple access sites (transaortic,axillary, carotid,apical and femoral). We had an experience of 500 hundreds balloon-expandable Edwards/Sapien Bioprosthesis (Edwards Life-sciences Inc., Orange,CA) with transapical approach (passage through the apex of left ventricle after left antero-lateral thoracotomy). Initially, we used 
general anesthesia according to scientific literature and our department experience. This choice was influenced by the operator's learning curve and the new procedure we were dealing with. The improvement of the surgeons and the evolution of device had required a change in the management of cardiac anesthesia for this patients, in order to reduce their days of hospitalization and peri/post-procedural complications.

Hence, we analysed our patient and evaluated the surgical/procedural needs in transapical aortic valve implantation (TAAVI, Table 2):

- $\quad$ immobility of the patient;

- $\quad$ hemodynamic stability;

- $\quad$ control of bleeding;

- control of rhythm;

- $\quad$ optimal neurological monitoring;

- $\quad$ management of airways and mechanical ventilation;

- $\quad$ check of the prosthesis implantation with transesophageal;

- Prevention of procedural complications.

\begin{tabular}{|c|c|}
\hline \multicolumn{2}{|c|}{ Complications short-term in transcatheter aortic- valve implantation } \\
\hline Cardiac & $\begin{array}{c}\text { Annular rupture } \\
\text { Ventricular rupture } \\
\text { Conduction disturbances/Arrhythmia } \\
\text { Coronary Ostia occlusion } \\
\text { Pericardial effusion } \\
\text { Post procedural aortic regurgitation }\end{array}$ \\
\hline Vascular & $\begin{array}{c}\text { Aorto/lliac rupture } \\
\text { Aortic dissection } \\
\text { Damage of the site of sheaths' insertion (femoral, axillary, } \\
\text { carotid) } \\
\text { Bleeding of the site of sheaths' insertion }\end{array}$ \\
\hline Device & $\begin{array}{c}\text { Valve malposition } \\
\text { Device embolization }\end{array}$ \\
\hline Neurological & $\begin{array}{l}\text { Stroke } \\
\text { TIA }\end{array}$ \\
\hline Respiratory & $\begin{array}{l}\text { Respiratory failure } \\
\text { Pleural effusion } \\
\text { Pneumothorax }\end{array}$ \\
\hline Other & $\begin{array}{c}\text { Bleeding } \\
\text { Acute renal failure }\end{array}$ \\
\hline
\end{tabular}

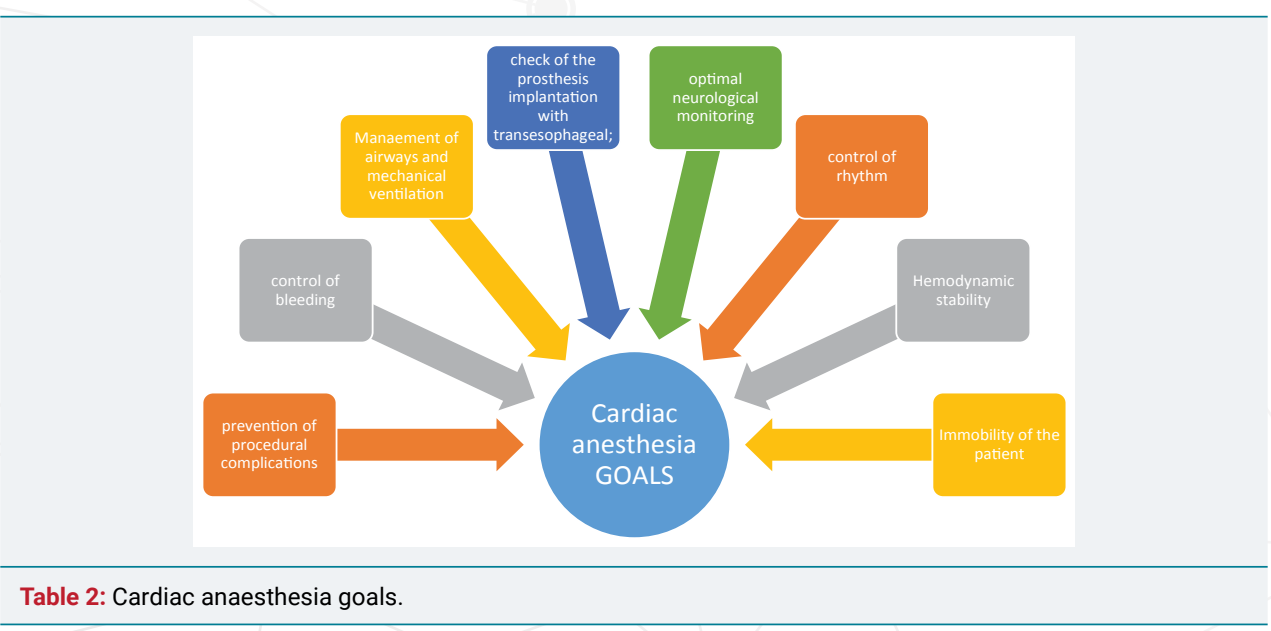


According to them, we updated our anesthesia management. All of the patients were evaluated by heart team (cardiologists, cardiac surgeons, and anaesthesists) and they were studied to have a complete and detailed preoperative patient's view in order to stratify the risks and avoid the complications. We sustained that the well-informed physician in TAAVI procedure was fundamental to anticipate and manage the minor and major adverse events in TAAVI patients by a correct anesthesia, analgesia and procedural monitoring.

At the beginning, the induction was done with propofol $(1 \mathrm{mg} / \mathrm{Kg} / \mathrm{IV}$, no rapid bolus) and then the maintenance infusion should immediately follow induction dose. According to heart team, if the patient could be extubated after the procedure, we used propofol (a dose of 0.02-0.06 mg/ $\mathrm{kg} / \mathrm{min}$ IV) and Desflurane as volatile anesthetic drug, because its rapid onset and offset and its low solubility in the blood allowing the weaning and extubation in the theatre. Otherwise, if the procedure should be complex or occurring complications, we shifted from desflurane to propofol intravenous continuous infusion $(4 \mathrm{mg} / \mathrm{Kg} / \mathrm{h})$. During administration of propofol we checked continuously patient's condition, response, and changes in vital signs. Moreover, we used low dose of fentanil for intubation $(0.2 \mathrm{mg} \mathrm{IV}, 1-5 \mathrm{mcg} / \mathrm{kg})$ and Cisatracurium besilate $(0.12-0 . .2 \mathrm{mg} / \mathrm{Kg})$ or Rocuronium bromide $(0.6-1.2 \mathrm{mg} / \mathrm{Kg}$ usually $1 \mathrm{mg} / \mathrm{kg}$ ). We avoided midazolam and high dose of opiates because the administrations of them were associated to high incidence of postoperative delirium in elderly. Propofol and desflurane were optimal for TAAVI patients in order to improve the management of peri- and postoperative period, prevent the complications and reduce the incidence of delirium considerably (Figure 1). The analgesia was supported by Morphin (10$20 \mathrm{mg} / 50 \mathrm{cc} \mathrm{SF}$ in elastamer) and acetaminophen. Post procedural management is based on the monitoring of patient hemodynamic, respiratory and general parameters. The goals was the rapid metabolization of anesthesia, correct and quickly mechanical ventilation weaning, control of bleeding, stabilization of hemodynamic value and correct time diuresis.

\section{Conclusion}

The well organized cardiac anesthesia in TAAVI patient was extremely important and relevant in order to prevent complications or to control the delirium. Our protocol, propofol with desflurane, have showed a lower incidence of delirium than the common general anesthesia. In addition, the combination of heart team and high-quality cardiac anesthesia had demonstrated an optimal prevention and management of the procedural complication and patient's complication, hence a reduction of hospitalization.

\section{Human rights statements and informed consent}

All procedures followed were in accordance with the ethical standards of the responsible committee on human experimentation (institutional and national) and with the Helsinki Declaration of 1964 and later revisions.

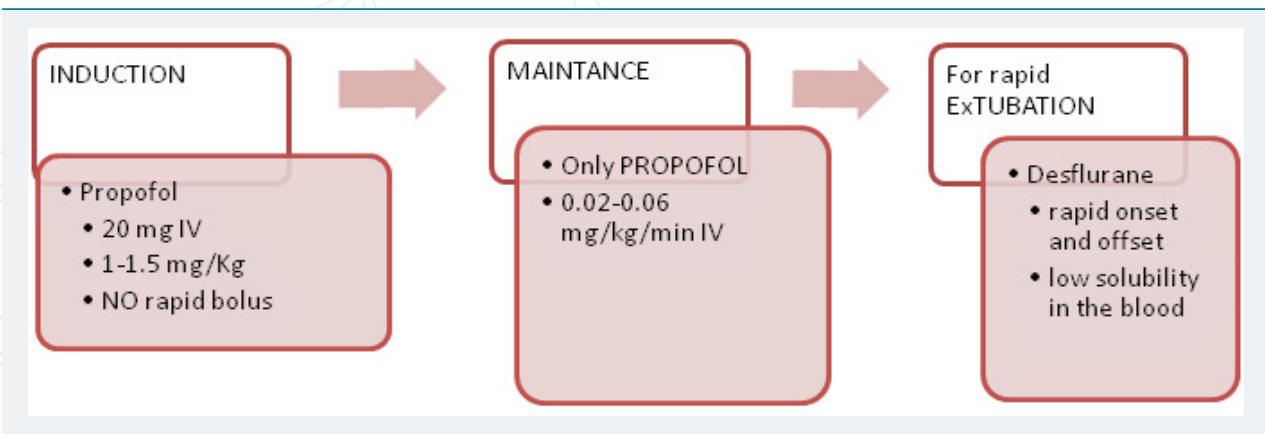

Figure 1: Patient 24, varying maximum activity in visual comparison of $\mathrm{I}-131$ scintigram (1a) with the Tc-99m- $\mathrm{O}_{4}$ scintigram (1b). Grid image in Figure 1a highlighted by the use of a high-energy collimator. 


\section{References}

1. Biancari $F, D^{\prime}$ Errigo $P$, Rosato $S$, Pol M, Tamburino $C$, et al. Transcatheter aortic valve replacement in nonagenarians: early and intermediate outcome from the OBSERVANT study and meta-analysis of the literature. Heart Vessels. 2017; 32: 157-165. Ref.: https://goo.gl/jKHnDP

2. Stanska A, Jagielak D, Brzezinski M, Zembala M, Wojakowski W, et al. Improvement of quality of life following transcatheter aortic valve implantation in the elderly: A multi-centre study based on the Polish national TAVI registry. Kardiol Pol. 2017; 75: 13-20. Ref.: https://goo.gl/UgGSNE

3. Antinori A, Arendt G, Becker JT. HHS Public Access. 2015; 69: 1789-1799.

4. Vahanian $\mathrm{A}$, Urena $\mathrm{M}$, Walther $\mathrm{T}$, Treede $\mathrm{H}$, Wendler $\mathrm{O}$, et al. Eurolntervention Thirty-day outcomes in patients at intermediate risk for surgery from the SAPIEN 3 European approval trial. Eurolntervention. 2017; 12: 235-243. Ref.: https://goo.gl/UC19vb

5. Huang PH, Eisenhauer AC. Transcatheter aortic valve replacement using the Edwards SAPIEN transcatheter heart valves. Cardiol Clin. 2013; 31: 337-350. Ref.: https://goo.gl/QUMyWm

6. Varghese V, George JC. Evolution in transcatheter aortic valve replacement: The Core Valve? selfexpanding prosthetic aortic valve. Interv Cardiol. 2012; Ref.: https://goo.gl/wW1kh4 